\title{
GMR
}

\section{Elevated expression of CXCR4 and correlation with clinicopathological features and prognosis of non-small cell lung cancer patients: a meta-analysis}

\author{
H. Wang ${ }^{1,2 *}, \mathrm{~F} \mathrm{Xie}^{3 *}$, Z. $\mathrm{Hu}^{2}$ and L. Chen ${ }^{2}$ \\ ${ }^{1}$ Qilu Hospital of Shandong University, Jinan, China \\ 2Department of Nephrology, The Forth Hospital of Jinan City, Jinan, China \\ ${ }^{3}$ Department of Nature Products Chemistry, \\ Key Lab of Chemical Biology (Ministry of Education), \\ School of Pharmaceutical Sciences, Shandong University, Jinan, China \\ ${ }^{*}$ These authors contributed equally to this study. \\ Corresponding author: Z. Hu \\ E-mail: huzhao108@126.com
}

Genet. Mol. Res. 14 (4): 17893-17903 (2015)

Received August 27, 2015

Accepted October 11, 2015

Published December 22, 2015

DOI http://dx.doi.org/10.4238/2015.December.22.14

\begin{abstract}
The specific correlation between CXCR4 expression and survival in non-small cell lung cancer (NSCLC) has been investigated independently; however, these have yielded inconsistent results. Therefore, we examined the exact relationship between CXCR4 expression and NSCLC in this meta-analysis. The bibliographic databases in English and Chinese were carefully searched and data regarding the prognostic value of CXCR4 and its association with pathological parameters of NSCLC were collected. Pooled odds ratios (OR) with $95 \%$ confidence interval $(\mathrm{Cl})$ were applied. A total of twelve studies (CXCR4 positive cases $=565$, CXCR4 negative $=755 ; 2003-2013$ ) that matched our predefined criteria were finally incorporated into our study. The pooled OR revealed that expression of CXCR4 in NSCLC patients was apparently correlated with lymphatic
\end{abstract}


metastasis, distant metastasis, and TNM stages (lymphatic metastasis: OR $=1.91,95 \% \mathrm{Cl}=1.21-3.27, \mathrm{P}=0.018 ;$ distant metastasis: $\mathrm{OR}=4.81,95 \% \mathrm{Cl}$ $=1.69-13.66, \mathrm{P}=0.003 ;$ TNM stages: $\mathrm{OR}=3.91,95 \% \mathrm{Cl}=1.22-12.55$, $P=0.022$ ). Positive expression of CXCR4 was also strongly correlated with a shorter overall survival (OS) rate in NSCLC patients (hazard ratio $=2.10,95 \% \mathrm{Cl}=1.21-2.99, \mathrm{P}<0.05)$. Further stratification by ethnicity indicated a negative association between CXCR4 expression and NSCLC development and prognosis in Asians NSCLC patients in all four models ( $P$ $<0.05)$. This indicated that elevated CXCR4 expression may be correlated with aggressive metastasis, advanced TNM stages, and shorter OS rate in NSCLC patients, suggesting a poor prognostic outcome of this disease.

Key words: CXCR4; Non-small cell lung cancer; Protein expression; Meta-analysis

\section{INTRODUCTION}

Non-small-cell lung cancer (NSCLC) is medically regarded as the representative form of lung cancer that accounts for approximately 80 to $90 \%$ of all lung cancers; it remains the leading cause of cancer-related mortality worldwide (Cui et al., 2013; Zhu et al., 2013). According to the criterion of histology, NSCLC can be further classified into several types, such as large cell carcinoma, adenocarcinoma, and squamous cell carcinoma; the two major histological subtypes of NSCLC are adenocarcinoma and squamous cell carcinoma (Tran, 2013; Ao et al., 2014). An estimated 30,000 new NSCLC cases are being diagnosed yearly in the United Kingdom (Meek et al., 2010). Chiefly, because of the silent symptoms of NSCLC during its early stages, and tendency to metastasize during its latter stages, curative resection is only implemented in $25-30 \%$ of the patients diagnosed with NSCLC (Jafri et al., 2013; Remon et al., 2013). Studies have also shown that the overall survival (OS) rate of NSCLC patients is extremely low at $\sim 15 \%$; the prognosis chiefly depends on the stages of NSCLC (Campbell et al., 2013; Lee et al., 2013). Epidemiologically, tobacco smoking and secondhand smoke, air pollution, and exposure to severe radiation are all factors increasing the occurrence and severity of NSCLC (Sarchianaki et al., 2014). So far, a myriad of studies have shown an abnormal expression of CXC chemokine receptor 4 (CXCR4) in patients with NSCLC; therefore, this is believed to be a possible biomarker for prognosis of NSCLC (Choi et al., 2014; Wang et al., 2014).

CXCR4, a seven-transmembrane trimeric G-protein-coupled receptor, is the most common chemokine receptor expressed by tumor cells (Na et al., 2008). Chemokines are critical contributors driving tumor cell invasion and metastasis, modulating the trafficking and extravasation of leukocytes, especially during the progression of inflammation, infection, and tissue damage (Choi et al., 2014). Therefore, CXCR4 and its activation may be responsible for the migration and differentiation of tumor cell lines, and is therefore believed to be related to the advanced stage and poorer survival of human tumors (Otsuka et al., 2011). Activated expression of CXCR4 plays a role in tumorigenicity, cell proliferation, angiogenesis, and metastasis in more than twenty types of cancers, including breast cancer, lung cancer, pancreatic cancer, and prostate cancer; recently, CXCR4 has been suggested to be a potential prognostic biomarker for these malignancies (Holland et al., 2013; Delongchamps et al., 2014; Deng et al., 2014). Significantly, all NSCLC cell lines have been revealed to express CXCR4 on the cell surface. Additionally, patients diagnosed with 
NSCLC accompanied by clinical metastasis are believed to show a high level of CXCR4 mRNA expression in their tissue specimens, compared to the levels seen in tissues obtained from patients without metastasis. This suggested that the activation of CXCR4 increases metastasis-associated behavior, such as cell invasion and migration (Al Zobair et al., 2013). Finally, we hypothesized that the correlation between abnormal expression of CXCR4 and the invasion and metastasis of human NSCLC cell lines might play a significant role in the progression and prognosis of NSCLC. A number of studies conducted over the past few decades have shown the close relationship between aberrant expression of CXCR4 and NSCLC prognosis; however, other investigators have presented different viewpoints (Lee et al., 2011; Al Zobair et al., 2013). Therefore, the possible prognostic value of CXCR4 in patients with NSCLC was evaluated in this meta-analysis to confirm the potential role of CXCR4 in tumor invasion, metastasis, and prognosis.

\section{MATERIAL AND METHODS}

\section{Data sources and key words}

Published papers assessing the correlation between CXCR4 protein expression and NSCLC survival were obtained from computerized databases [Embase, China BioMedicine (CBM), China National Knowledge Infrastructure (CNKI), PubMed, and Web of Science; updated as of June 31, 2014] utilizing select common key words ("Carcinoma, Non-Small-Cell Lung", "non-small cell lung carcinomas", "non-small cell lung cancer", "non small cell lung cancer", "non-small-cell lung cancer", "non small cell lung carcinoma" or "NSCLC" and "Receptors, CXCR4", "CXCR4 protein, human", "CXCR4", "chemokine (C-X-C motif) receptor 4", "chemokine (C-X-C motif) receptor 4", "CXCR4 Receptor", "LESTR", "Fusin”, "Leukocyte-Derived Seven-Transmembrane Domain Receptor", "Leukocyte-Derived Seven Transmembrane Domain Receptor", "CXC Chemokine Receptor 4", "CXCR4 Receptors", “C-X-C Chemokine Receptor type 4", or "CXCR-4”). The data collection was unlimited, and only articles published in English and Chinese were extracted for this analysis.

\section{Study selection}

For enrollment in this meta-analysis, the papers had to fulfill the following inclusion criteria: 1) publication focused on the relationship between CXCR4 protein expression and NSCLC prognosis; 2) patients with pathologically confirmed NSCLC (Xu and Lu, 2014); 3) data regarding the level of expression of the CXCR4 protein, OS status of NSCLC, and sample number must be supplied; 4) published studies with full text; and 5) the latest or completed studies included when the extracted studies were published by the same authors. Papers were excluded based on the following exclusion criteria: 1) papers that showed inconsistent opinions for the positive or negative expression of CXCR4 in the tissues of patients with NSCLC; 2) articles published in duplicate, or poor-quality articles, especially with respect to the methodological assessment; 3) studies that reported experiments on animals, or non-original articles, literature reviews, and reports.

\section{Data extraction}

Two investigators extracted information jointly from the retrieved papers to reduce the bias and enhance the credibility, and arrived at a consensus on all factors. When there were disagreements or differences in opinions, a discussion or reexamination was held with a third 
reviewer. The following relevant data were extracted from the eligible studies: surname of the first author, date of publication, regional distribution information (country/ethnicity), study design, sample size, age, gender, source of samples, and detection method for CXCR4 protein expression, expression level of CXCR4 protein in NSCLC patients, and OS evaluation. All authors approved the final determinant of studies to be enrolled.

\section{Quality assessment}

In order to quantitatively aggregate the OS results of NSCLC patients, the effects of CXCR4 protein expression on the survival situation were carefully measured using a checklist, including the Reporting Recommendations for Tumor Marker Prognostic Studies (REMARK; which analyzes 20 factors from the published prognostic studies of tumor markers, covering the relevant sections such as the introduction, methods, results, and discussion (REMARK). This recommendation is a useful tool that allows one to assemble the information required to judge the quality and relevance of the study, instead of a simple standard for quality assessment. The quality was assessed using the Newcastle-Ottawa Scale (NOS) criteria to decide whether the study in question is of high quality; this relied on three aspects: 1) subject selection: $0-4 ; 2$ ) comparability of subject: 0-2; 3) clinical outcome: 0-3 (Stang, 2010). The NOS criteria were scored from 0 (lowest) to 9 (highest); scores 0 to 6 indicated a low quality, while scores ranging from 7 to 9 were of high quality.

\section{Statistical analysis}

The obtained eligible information was quantitatively aggregated by applying the pooled odds ratios $(\mathrm{OR})$ with $95 \%$ confidence interval $(\mathrm{Cl})$ to calculate the effect of each study, using the $Z$ test. In order to supply quantitative evidence of all selected studies and minimize the variance of the summary $\mathrm{OR}$ with $95 \% \mathrm{Cl}$, this statistical meta-analyses employed a randomeffect model (DerSimonian and Laird method) or a fixed-effect model (Mantel-Haenszel method) of independent studies, where data from enrolled studies could be combined. The random-effect model was applied when heterogeneity existed among the studies, while the fixed-effect model was employed when there was a fine homogeneity between the studies. Cochran's Q-statistic evaluated the heterogeneity across the involved studies $(P<0.05$ was considered to be statistically significant); this was further measured by the $l^{2}$ test $(0 \%$, no heterogeneity; $100 \%$, maximal heterogeneity), considering a low statistical power of the Cochran's Q-statistic (Peters et al., 2006; Jackson et al., 2012). A subgroup meta-analyses by ethnicity was conducted to explore the potential heterogeneity sources and for a secondary verification of the overall results. A Funnel plot assessed the presence of publication bias that might affect the accuracy of the overall estimates, and the symmetry of the funnel plot was further evaluated by the Egger linear regression test (Zintzaras and loannidis, 2005).

\section{RESULTS}

\section{Studies included}

Figure 1 displayed the steps in study selection. A total of 187 reports were initially retrieved by electronic database and manual search; only 86 papers were retained after the removal of duplicates $(N=1)$, letters, reviews, or meta-analyses $(N=23)$, non-human studies $(N=40)$, and 
studies unrelated to the research topic $(\mathrm{N}=37)$. Furthermore, an additional 72 studies that were not case-control studies $(\mathrm{N}=19)$, not relevant to the CXCR4 protein $(\mathrm{N}=17)$, or irrelevant to NSCLC $(\mathrm{N}=36)$, were excluded. In the final selection step, 12 of 14 studies were extracted; the remaining 2 were excluded for not supplying enough information. Twelve full-text studies conformed to our selection criteria, and provided information on the correlation between CXCR4 protein expression and prognosis of NSCLC (Takanami, 2003; Spano et al., 2004; Su et al., 2005; Na et al., 2008; Suzuki et al., 2008; Reckamp et al., 2009; Wagner et al., 2009; Otsuka et al., 2011; Franco et al., 2012; Al Zobair et al., 2013; Wang et al., 2011, 2014). Demographic information, baseline characteristics, and methodological quality of the extracted studies are summarized in Tables 1 and 2. Six studies were performed in Asians, and the remaining 6 studies were conducted in populations of Caucasian descent; the studies included analyzed a total of 1320 NSCLC patients $(\mathrm{CXCR} 4$ positive $=565, \mathrm{CXCR} 4$ negative $=755)$. Protein expressions of CXCR4 in the cytoplasm were detected by streptavidin peroxidase $(N=4)$, EnVision $(N=2)$, Leica-Vision $(N=1)$, avidin biotin complex $(N=4)$, and alkaline phosphatase anti-alkaline phosphatase $(N=1)$. The quality scores of all studies included were higher than 6 (high quality).

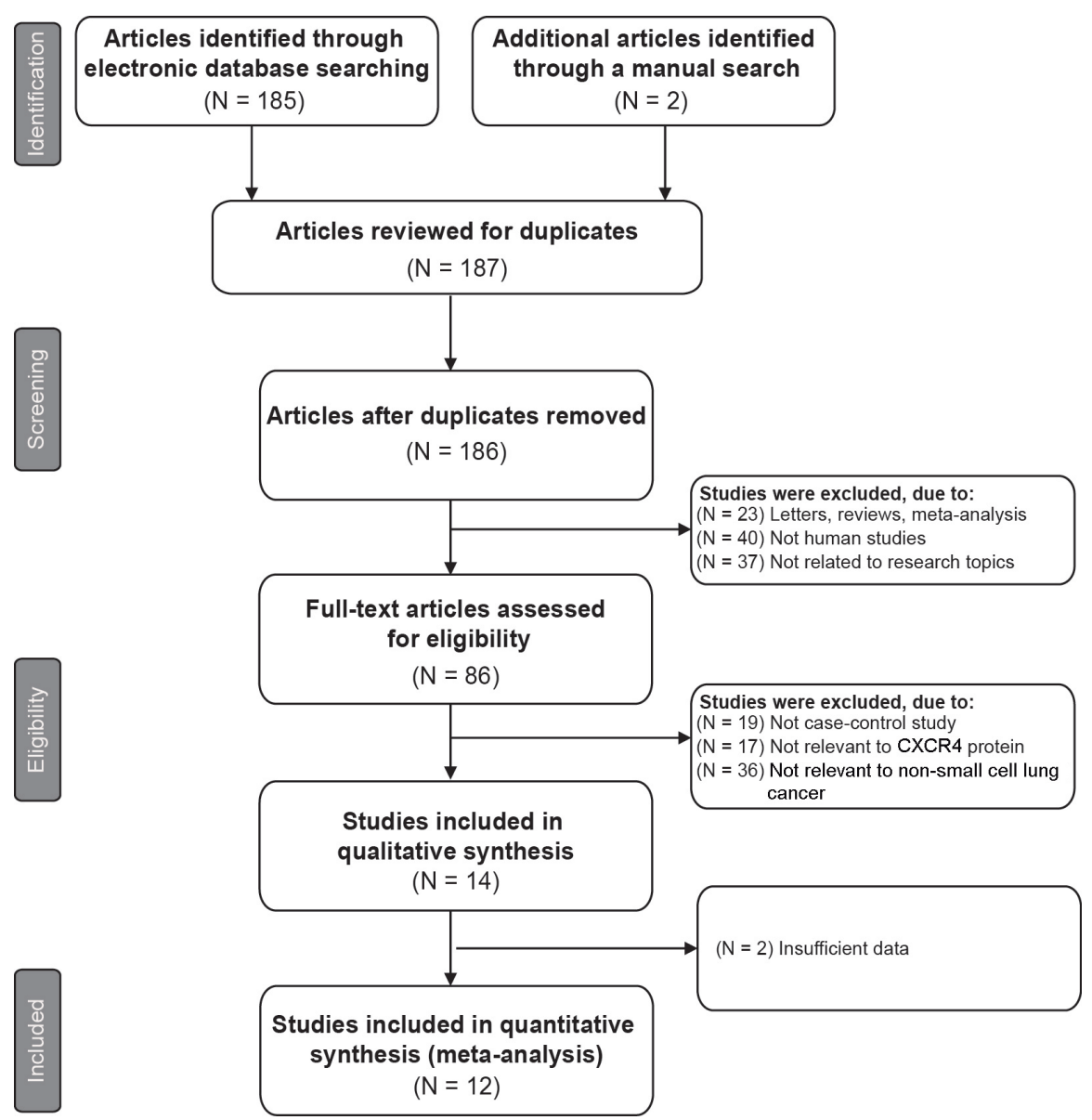

Figure 1. Flow chart presenting the study selection procedure. Twelve cohort studies were included in this meta-analysis. 


\begin{tabular}{|c|c|c|c|c|c|c|c|c|c|c|}
\hline \multirow[t]{2}{*}{ First author } & \multirow[t]{2}{*}{ Year } & \multirow[t]{2}{*}{ Ethnicity } & \multirow[t]{2}{*}{ Location } & \multicolumn{2}{|c|}{ Number } & \multicolumn{2}{|c|}{ Gender (M/F) } & \multicolumn{2}{|c|}{ Age (years) } & \multirow[t]{2}{*}{ Method } \\
\hline & & & & Positive & Negative & Positive & Negative & Positive & Negative & \\
\hline Wang L & 2014 & Asians & Cytoplasmic & 63 & 42 & - & - & - & - & $\mathrm{SP}$ \\
\hline Al Zobair AA & 2013 & Asians & Cytoplasmic & 62 & 63 & $42 / 20$ & $45 / 15$ & & & SP \\
\hline Franco R & 2012 & Caucasians & Cytoplasmic & 33 & 12 & \multicolumn{2}{|c|}{$31 / 14$} & \multicolumn{2}{|c|}{$74.2(48-81)$} & $A B C$ \\
\hline Wang M & 2011 & Asians & Cytoplasmic & 117 & 91 & $74 / 43$ & $54 / 37$ & \multicolumn{2}{|c|}{$59.8(35-76)$} & SP \\
\hline Otsuka S & 2011 & Caucasians & Cytoplasmic & 29 & 141 & $19 / 10$ & $67 / 74$ & \multicolumn{2}{|c|}{$67.0(32-88)$} & EnVision \\
\hline Wagner PL-a & 2009 & Caucasians & Nuclear & 62 & 92 & $17 / 45$ & $29 / 63$ & \multicolumn{2}{|c|}{$67.0 \pm 8.0$} & Leica-Vision \\
\hline Wagner PL-b & 2009 & Caucasians & Cytoplasmic & 47 & 107 & $15 / 32$ & $31 / 76$ & \multicolumn{2}{|c|}{$67.0 \pm 8.0$} & Leica-Vision \\
\hline $\mathrm{Na} I \mathrm{IK}-\mathrm{a}$ & 2008 & Caucasians & Cytoplasmic & 44 & 2 & \multicolumn{2}{|c|}{$29 / 17$} & \multicolumn{2}{|c|}{60.5} & APAAP \\
\hline $\mathrm{Na}$ IK-b & 2008 & Caucasians & Nuclear & 5 & 36 & \multicolumn{2}{|c|}{$29 / 17$} & \multicolumn{2}{|c|}{60.5} & APAAP \\
\hline Su L & 2005 & Asians & Cytoplasmic & 17 & 17 & $9 / 8$ & $10 / 7$ & $59.2 \pm 6.8$ & $62.4 \pm 10.0$ & EnVision \\
\hline Spano JP & 2004 & Caucasians & Cytoplasmic & 17 & 44 & $12 / 36$ & $5 / 8$ & $61.7(40-79)$ & $60.2(38-84)$ & $\mathrm{ABC}$ \\
\hline Takanami I & 2003 & Asians & Cytoplasmic & 42 & 29 & - & - & - & - & $A B C$ \\
\hline Reckamp KL & 2009 & Caucasians & Cytoplasmic & 5 & 11 & $2 / 3$ & $6 / 5$ & $74.0 \pm 6.0$ & $67.0 \pm 11.0$ & $A B C$ \\
\hline Suzuki M & 2008 & Asians & Cytoplasmic & 22 & 68 & - & - & - & - & SP \\
\hline
\end{tabular}

$\mathrm{M}=$ male; $\mathrm{F}=$ female; $\mathrm{SP}=$ streptavidin peroxidase; $\mathrm{ABC}=$ avidin biotin complex; $\mathrm{APAAP}=$ alkaline phosphatase anti-alkaline phosphatase.

Table 2. Methodological quality of studies included in the final analysis based on the Newcastle-Ottawa scale for assessment of the quality of case-control studies.

\begin{tabular}{|c|c|c|c|c|c|c|c|c|c|}
\hline \multirow[t]{2}{*}{ First author } & \multicolumn{4}{|c|}{ Selection (score) } & \multirow{2}{*}{$\begin{array}{c}\text { Comparability (score) } \\
\text { Control for } \\
\text { important or } \\
\text { additional } \\
\text { factors }\end{array}$} & \multicolumn{4}{|c|}{ Exposure (score) } \\
\hline & $\begin{array}{l}\text { Adequate } \\
\text { definition of } \\
\text { patients }\end{array}$ & $\begin{array}{l}\text { Representativeness } \\
\text { of patients }\end{array}$ & $\begin{array}{l}\text { Selection } \\
\text { of controls }\end{array}$ & $\begin{array}{l}\text { Definition of } \\
\text { controls }\end{array}$ & & $\begin{array}{l}\text { Ascertainment } \\
\text { of exposure } \\
\text { (blinding) }\end{array}$ & $\begin{array}{c}\text { Same } \\
\text { method of } \\
\text { ascertainment } \\
\text { for participants }\end{array}$ & $\begin{array}{c}\text { Nonresponse } \\
\text { rate }^{*}\end{array}$ & $\begin{array}{l}\text { Total } \\
\text { score }^{\star *}\end{array}$ \\
\hline Wang L & 1 & 1 & 1 & 0 & 1 & 0 & 1 & 1 & 6 \\
\hline Al Zobair AA & 1 & 1 & 1 & 0 & 1 & 1 & 1 & 1 & 7 \\
\hline Franco R & 1 & 1 & 1 & 0 & 1 & 0 & 1 & 1 & 6 \\
\hline Wang M & 1 & 0 & 1 & 1 & 1 & 1 & 1 & 1 & 7 \\
\hline Otsuka S & 1 & 1 & 1 & 1 & 1 & 0 & 1 & 1 & 7 \\
\hline Wagner PL & 1 & 0 & 1 & 1 & 1 & 1 & 1 & 1 & 7 \\
\hline $\mathrm{Na} I \mathrm{~K}$ & 1 & 0 & 1 & 1 & 1 & 0 & 1 & 1 & 6 \\
\hline SuL & 1 & 1 & 1 & 1 & 0 & 0 & 1 & 1 & 6 \\
\hline Spano JP & 1 & 0 & 1 & 1 & 1 & 0 & 1 & 1 & 6 \\
\hline Takanami I & 1 & 1 & 0 & 1 & 1 & 0 & 1 & 1 & 6 \\
\hline Reckamp KL & 1 & 0 & 1 & 1 & 0 & 1 & 1 & 1 & 6 \\
\hline Suzuki M & 1 & 0 & 1 & 1 & 1 & 1 & 1 & 0 & 6 \\
\hline
\end{tabular}

*In the absence of a significant difference in the response rate of both groups as determined using the $\chi^{2}$ test $(P>0.05)$, one point was awarded. ${ }^{* *}$ Total score could range between 0-9 points.

\section{Expression of the CXCR4 protein in NSCLC}

Fixed-effect analyses were applied to pool the data in order to explore the relationship between CXCR4 protein expression and NSCLC prognosis, because of the lack of heterogeneity $\left(I^{2}=34.3 \%, \mathrm{P}=0.179\right)$. As shown in Figure 2, the pooled OR indicated that the expression of CXCR4 in NSCLC patients was correlated with lymphatic metastasis $(\mathrm{OR}=1.91,95 \% \mathrm{Cl}=1.21$ 3.27, $P=0.018$ ). We also observed an obvious negative correlation between CXCR4 expression and deteriorated distant metastasis in NSCLC patients, compared to those with no detectable expression of CXCR4 $(\mathrm{OR}=4.81,95 \% \mathrm{Cl}=1.69-13.66, \mathrm{P}=0.003)$. Furthermore, $\mathrm{CXCR} 4$ expression indicated a higher TNM stage $(\mathrm{OR}=3.91,95 \% \mathrm{Cl}=1.22-12.55, \mathrm{P}=0.022)$. Therefore, 
positive expression of CXCR4 was strongly correlated with a shorter OS rate in NSCLC patients, compared to the negative expression $(\mathrm{HR}=2.10,95 \% \mathrm{Cl}=1.21-2.99, \mathrm{P}=0.000)$.

Further stratified analyses based on ethnicity demonstrated a negative relationship between CXCR4 expression and NSCLC development and prognosis among the Asian population under all four models (lymphatic metastasis: $\mathrm{OR}=2.52,95 \% \mathrm{Cl}=1.51-4.23, \mathrm{P}=0.000$; distant metastases: $\mathrm{OR}=10.73,95 \% \mathrm{Cl}: 4.14-27.83, \mathrm{P}=0.000$; $\mathrm{LNM}$ stages: $\mathrm{OR}=6.66,95 \% \mathrm{Cl}=2.80-$ 15.81, $\mathrm{P}=0.000$; overall survival: $\mathrm{HR}=2.32,95 \% \mathrm{Cl}=1.41-3.23, \mathrm{P}=0.000$; respectively) (Figure 3 ). However, this association was not seen in the Caucasian population (all $P>0.05$ ).

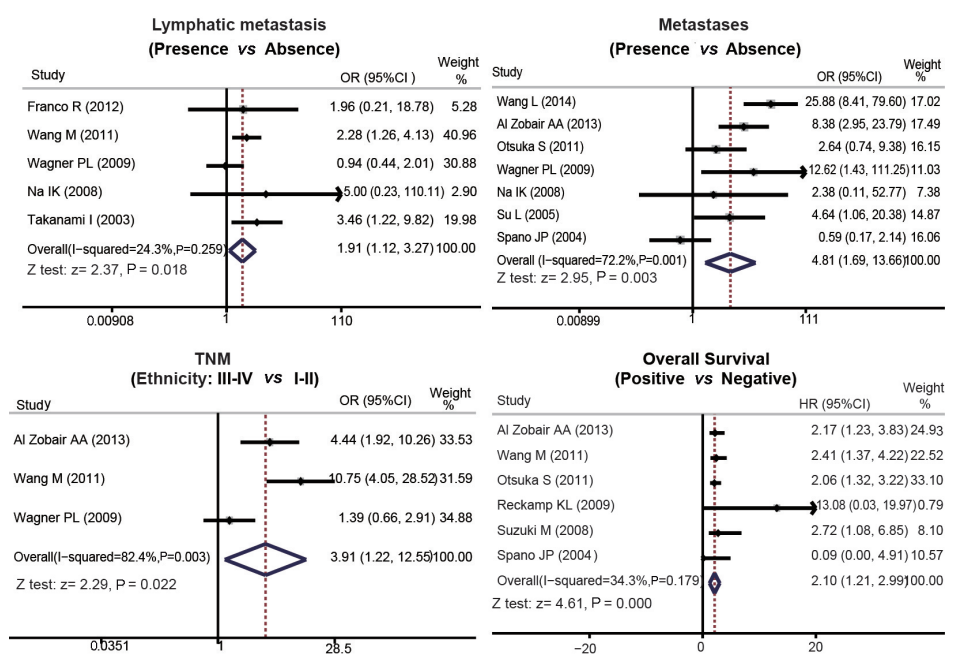

Figure 2. Forest plots of the relationship between abnormal CXCR4 expression and pathological characteristics, and between prognosis of patients and non-small cell lung cancer.
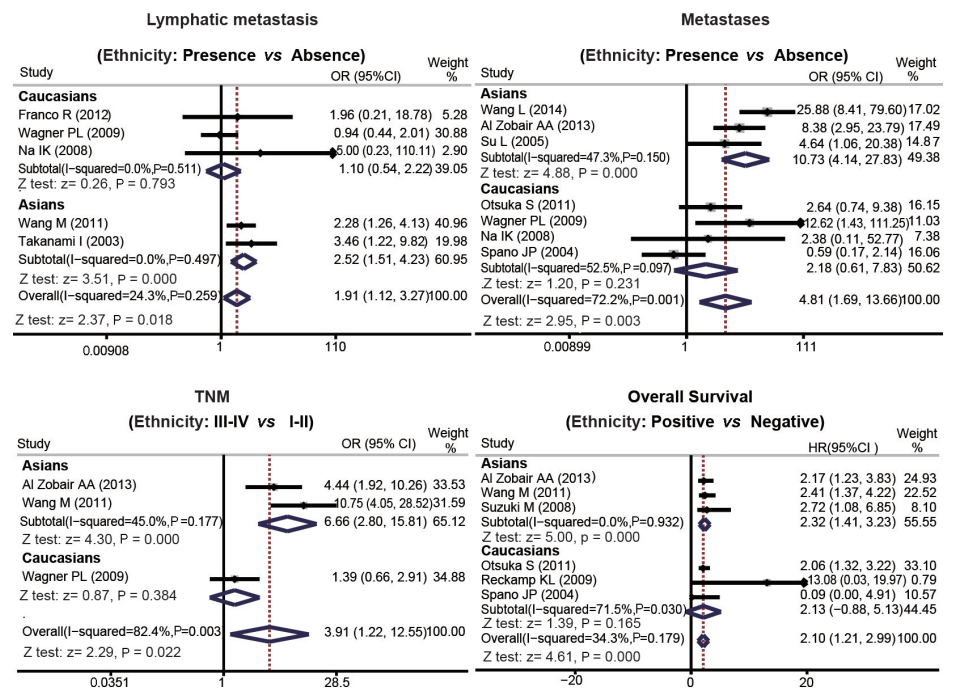

Figure 3. Subgroup analysis (by ethnicity) of the relationships between abnormal CXCR4 expression and pathological characteristics and prognosis of patients with non-small cell lung cancer. 


\section{Publication bias}

The graphical funnel plots of the ten studies analyzed by the OS model was symmetrical, and the Egger test failed to detect a publication bias $(P=0.006$; Figure 4). However, the shape of the funnel plots of the studies analyzed by the other three models provided a strong evidence of asymmetry, with the Egger test showing the presence of a publication bias (all P > 0.05).

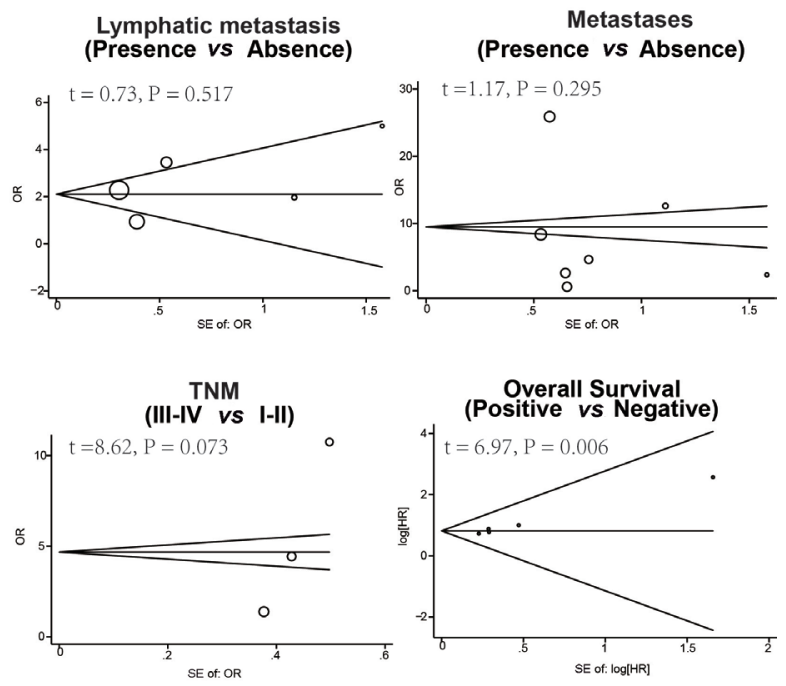

Figure 4. Publication bias for the summary odds ratio coefficients based on the association between abnormal CXCR4 expression and pathological characteristics, and prognosis of patients with non-small cell lung cancer.

\section{DISCUSSION}

The potential relationship between CXCR4 and NSCLC prognosis has been widely investigated; additionally, the significant role of CXCR4 in the proliferation and metastasis of various human tumors has also been demonstrated (Sun et al., 2010; Liang et al., 2014). In this meta-analysis, we attempted to explore the association between the levels of CXCR4 expression and the clinicopathological features and prognosis of NSCLC. Our analyses revealed that an elevation in the expression level of CXCR4 was potentially correlated with deteriorated pathological characteristics and poor survival rate of NSCLC patients.

Lung cancer, particularly NSCLC, is the leading cause of cancer-related mortality worldwide, with less than $15 \%$ of the patients surviving beyond 5 years after diagnosis or treatment (Al Zobair et al., 2013). Therefore, the identification of molecular biomarkers involved in early tumorigenesis or metastasis/prognosis of NSCLC may be helpful for the development of new targeted therapies (Lang et al., 2014; Miller et al., 2014). Among these biomarkers, CXCR4, which is functionally expressed on the cell surface of a number of cancer cells including NSCLC, may prove beneficial for the prediction of prognosis in NSCLC (Wang et al., 2011; Delongchamps et al., 2014). In addition, CXCR4 is not expressed on the cell surface of normal lung tissues (Spano et al., 2004). As demonstrated previously, CXCR4 plays a critical role in tumor cell proliferation and migration, and may also promote lymph node metastasis in several solid human tumors, including 
NSCLC (Pan et al., 2012; Choi et al., 2014). This supports the notion that the level of expression of CXCR4 on tumor cells may function as a crucial biomarker indicating the propensity of tumor cells to metastasize (Ok et al., 2012). In addition, CXCR4 may affect the transition of a tumor from a nonmetastatic to a malignant phenotype (Holland et al., 2006). Our meta-analysis indicated an increased level of CXCR4 expression in NSCLC cell lines, suggesting that the elevated concentration of CXCR4 might promote the invasion and metastasis of these tumor cells, and the transition of NSCLC from non-metastatic to its malignant type, thereby resulting in deterioration of NSCLC cells and leading to an advanced stage of this cancer. These might result in a significantly shorter OS rate and high incidence of cancer-related death. Consistent with our findings, Al Zobair et al. (2013) reported that the inhibition of CXCR4 expression in NSCLC patients may be an effective treatment strategy for this disease. Wang et al. (2011) reported that the expression levels of CXCR4 were independent prognostic factors affecting the OS of NSCLC patients, suggesting that CXCR4 expression may be a critical factor affecting NSCLC progression and angiogenesis. Xie et al. (2014) also supported the speculation that increased CXCR4 expression was a predictive factor for deteriorating prognosis of NSCLC patients, and that specific down-regulation of CXCR4 inhibited tumor cell growth, invasiveness, and migration.

Meanwhile, many other factors may influence the outcome of increased CXCR4 expression in patients diagnosed with NSCLC; therefore, a stratified analysis based on ethnicity was performed. This stratified analysis showed that CXCR4 expression was negatively correlated with the deterioration in pathological features and poor prognosis of Asian NSCLC patients. However, no such observation was made in the Caucasian population. One possible explanation of this phenomenon may be that the differences in ethnic background, life-style, or environment may affect the overall estimation.

Our study has several limitations that might weaken its validity. Firstly, some of the included studies have a relatively low sample size, which would adversely influence the statistical power of the study (to detect the differences between CXCR4-positive and -negative groups). Secondly, the age information was not available for 5 of the studies included (Takanami, 2003; Suzuki et al., 2008; Otsuka et al., 2011; Wang et al., 2011; Al Zobair et al., 2013); among these studies, two also did not present any gender information (Takanami, 2003; Suzuki et al., 2008). The method of detection of CXCR4 expression differed among the various studies; these may be possible sources of heterogeneity. Thirdly, there was an obvious publication biases in the most detected models; therefore, the results of this analysis should be accepted with caution. Finally, we only focused on positive or negative expression of CXCR4; that is, there is no consistent definition regarding the cut-off values of CXCR4 expression (high or low) at present.

In conclusion, our findings revealed that increased expression of CXCR4 may be significantly correlated with aggressive metastasis, advanced TNM stages, and shorter OS rate in NSCLC patients, suggesting a poor prognostic outcome of this disease. Further studies evaluating the biological significance of CXCR4 expression in the prognosis management of NSCLC patients are recommended, based on the above-mentioned limitations.

\section{Conflicts of interest}

The authors declare no conflict of interest.

\section{ACKNOWLEDGMENTS}

We would like to acknowledge the reviewers for their helpful comments on this paper. 


\section{REFERENCES}

Al Zobair AA, Al Obeidy BF, Yang L, Yang C, et al. (2013). Concomitant overexpression of EGFR and CXCR4 is associated with worse prognosis in a new molecular subtype of non-small cell lung cancer. Oncol. Rep. 29: 1524-1532.

Ao MH, Zhang H, Sakowski L, Sharma R, et al. (2014). The utility of a novel triple marker (combination of TTF1, napsin A, and p40) in the subclassification of non-small cell lung cancer. Hum. Pathol. 45: 926-934.

Campbell TM, Main MJ and Fitzgerald EM (2013). Functional expression of the voltage-gated $\mathrm{Na}^{+}$-channel Nav1.7 is necessary for EGF-mediated invasion in human non-small cell lung cancer cells. J. Cell Sci. 126: 4939-4949.

Choi YH, Burdick MD, Strieter BA, Mehrad B, et al. (2014). CXCR4, but not CXCR7, discriminates metastatic behavior in nonsmall cell lung cancer cells. Mol. Cancer Res. 12: 38-47.

Cui EH, Li HJ, Hua F, Wang B, et al. (2013). Serum microRNA 125b as a diagnostic or prognostic biomarker for advanced NSCLC patients receiving cisplatin-based chemotherapy. Acta Pharmacol. Sin. 34: 309-313.

Delongchamps NB, Beuvon F, Mathieu JR, Delmas S, et al. (2014). CXCR4 is highly expressed at the tumor front but not in the center of prostate cancers. World. J. Urol. [Epub ahead of print].

Deng L, Shang Y, Guo S, Liu C, et al. (2014). Ran GTPase protein promotes metastasis and invasion in pancreatic cancer by deregulating the expression of AR and CXCR4. Cancer Biol. Ther. 15: 1087-1093.

Franco R, Pirozzi G, Scala S, Cantile M, et al. (2012). CXCL12-binding receptors expression in non-small cell lung cancer relates to tumoral microvascular density and CXCR4 positive circulating tumoral cells in lung draining venous blood. Eur. J. Cardiothorac. Surg. 41: 368-375.

Holland JD, Kochetkova M, Akekawatchai C, Dottore M, et al. (2006). Differential functional activation of chemokine receptor CXCR4 is mediated by $\mathrm{G}$ proteins in breast cancer cells. Cancer Res. 66: 4117-4124.

Holland JD, Gyorffy B, Vogel R, Eckert K, et al. (2013). Combined Wnt/beta-catenin, Met, and CXCL12/CXCR4 signals characterize basal breast cancer and predict disease outcome. Cell. Rep. 5: 1214-1227.

Jackson D, White IR and Riley RD (2012). Quantifying the impact of between-study heterogeneity in multivariate metaanalyses. Stat. Med. 31: 3805-3820.

Jafri SH, Shi R and Mills G (2013). Advance lung cancer inflammation index (ALI) at diagnosis is a prognostic marker in patients with metastatic non-small cell lung cancer (NSCLC): a retrospective review. BMC Cancer 13: 158.

Lang Y, Xu S, Ma J, Wu J, et al. (2014). MicroRNA-429 induces tumorigenesis of human non-small cell lung cancer cells and targets multiple tumor suppressor genes. Biochem. Biophys. Res. Commun. 450: 154-159.

Lee SH, Suh IB, Lee EJ, Hur GY, et al. (2013). Relationships of coagulation factor XIII activity with cell-type and stage of nonsmall cell lung cancer. Yonsei. Med. J. 54: 1394-1399.

Lee YL, Kuo WH, Lin CW, Chen W, et al. (2011). Association of genetic polymorphisms of CXCL12/SDF1 gene and its receptor, CXCR4, to the susceptibility and prognosis of non-small cell lung cancer. Lung Cancer 73: 147-152.

Liang Z, Bian X and Shim H (2014). Inhibition of breast cancer metastasis with microRNA-302a by downregulation of CXCR4 expression. Breast Cancer Res. Treat. 146: 535-542.

Meek CL, Wallace AM, Forrest LM and McMillan DC (2010). The relationship between the insulin-like growth factor-1 axis, weight loss, an inflammation-based score and survival in patients with inoperable non-small cell lung cancer. Clin. Nutr. 29: 206-209.

Miller RE, Jones JC, Tometsko M, Blake ML, et al. (2014). RANKL inhibition blocks osteolytic lesions and reduces skeletal tumor burden in models of non-small-cell lung cancer bone metastases. J. Thorac. Oncol. 9: 345-354.

Na IK, Scheibenbogen C, Adam C, Stroux A, et al. (2008). Nuclear expression of CXCR4 in tumor cells of non-small cell lung cancer is correlated with lymph node metastasis. Hum. Pathol. 39: 1751-1755.

Ok S, Kim SM, Kim C, Nam D, et al. (2012). Emodin inhibits invasion and migration of prostate and lung cancer cells by downregulating the expression of chemokine receptor CXCR4. Immunopharmacol. Immun. 34: 768-778.

Otsuka S, Klimowicz AC, Kopciuk K, Petrillo SK, et al. (2011). CXCR4 overexpression is associated with poor outcome in females diagnosed with stage IV non-small cell lung cancer. J. Thorac. Oncol. 6: 1169-1178.

Pan $\mathrm{CH}$, Chen CW, Sheu MJ and Wu CH (2012). Salvianolic acid B inhibits SDF-1alpha-stimulated cell proliferation and migration of vascular smooth muscle cells by suppressing CXCR4 receptor. Vascul. Pharmacol. 56: 98-105.

Peters JL, Sutton AJ, Jones DR, Abrams KR, et al. (2006). Comparison of two methods to detect publication bias in metaanalysis. JAMA 295: 676-680.

Reckamp KL, Figlin RA, Burdick MD, Dubinett SM, et al. (2009). CXCR4 expression on circulating pan-cytokeratin positive cells is associated with survival in patients with advanced non-small cell lung cancer. BMC Cancer 9: 213.

Remon J, Lianes P, Martinez S, Velasco M, et al. (2013). Adjuvant treatment in resected non-small cell lung cancer: current and future issues. Crit. Rev. Oncol. Hematol. 88: 375-386.

Sarchianaki E, Derdas SP, Ntaoukakis M, Vakonaki E, et al. (2014). Detection and genotype analysis of human papillomavirus in non-small cell lung cancer patients. Tumour Biol. 35: 3203-3209. 
Spano JP, Andre F, Morat L, Sabatier L, et al. (2004). Chemokine receptor CXCR4 and early-stage non-small cell lung cancer: pattern of expression and correlation with outcome. Ann. Oncol. 15: 613-617.

Stang A (2010). Critical evaluation of the Newcastle-Ottawa scale for the assessment of the quality of nonrandomized studies in meta-analyses. Eur. J. Epidemiol. 25: 603-605.

Su L, Zhang J, Xu H, Wang Y, et al. (2005). Differential expression of CXCR4 is associated with the metastatic potential of human non-small cell lung cancer cells. Clin. Cancer Res. 11: 8273-8280.

Sun X, Cheng G, Hao M, Zheng J, et al. (2010). CXCL12/CXCR4/CXCR7 chemokine axis and cancer progression. Cancer Metastasis Rev. 29: 709-722.

Suzuki M, Mohamed S, Nakajima T, Kubo R, et al. (2008). Aberrant methylation of CXCL12 in non-small cell lung cancer is associated with an unfavorable prognosis. Int. J. Oncol. 33: 113-119.

Takanami I (2003). Overexpression of CCR7 mRNA in nonsmall cell lung cancer: correlation with lymph node metastasis. Int. J. Cancer 105: 186-189.

Tran QN (2013). A novel method for finding non-small cell lung cancer diagnosis biomarkers. BMC Med. Genomics 6: S11.

Wagner PL, Hyjek E, Vazquez MF, Meherally D, et al. (2009). CXCL12 and CXCR4 in adenocarcinoma of the lung: association with metastasis and survival. J. Thorac. Cardiovasc. Surg. 137: 615-621.

Wang L, Wang Z, Liu X and Liu F (2014). High-level C-X-C chemokine receptor type 4 expression correlates with brain-specific metastasis following complete resection of non-small cell lung cancer. Oncol. Lett. 7: 1871-1876.

Wang M, Chen GY, Song HT, Hong X, et al. (2011). Significance of CXCR4, phosphorylated STAT3 and VEGF-A expression in resected non-small cell lung cancer. Exp. Ther. Med. 2: 517-522.

Xie S, Zeng W, Fan G, Huang J, et al. (2014). Effect of CXCL12/CXCR4 on increasing the metastatic potential of non-small cell lung cancer in vitro is inhibited through the downregulation of CXCR4 chemokine receptor expression. Oncol. Lett. 7: $941-947$.

Xu YH and Lu S (2014). A meta-analysis of STAT3 and phospho-STAT3 expression and survival of patients with non-small-cell lung cancer. Eur. J. Surg. Oncol. 40: 311-317.

Zhu X, Li Y, Shen H, Li H, et al. (2013). miR-137 inhibits the proliferation of lung cancer cells by targeting Cdc42 and Cdk6. FEBS Lett. 587: 73-81.

Zintzaras E and loannidis JP (2005). HEGESMA: genome search meta-analysis and heterogeneity testing. Bioinformatics 21: 3672-3673. 